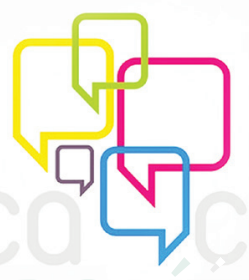

\title{
O papel do compositor da canção midiática como catalisador de processos de identificação cultural ${ }^{1}$
}

The role of the composer of the song media as a catalyst for processes of cultural identification

El papel del compositor de los medios de comunicación canción como un catalizador de los procesos de identificación cultural

\begin{abstract}
RESUMO
Este artigo desenvolve uma reflexão sobre o papel do compositor da canção midiática a partir da perspectiva de algumas das principais teorias da comunicação e da cultura. Busca-se analisar os elementos que atuam no processo criativo do compositor, considerando sua inserção na lógica de consumo e produção da indústria cultural e dos meios de comunicação de massa. A reflexão contrapõe duas visões sobre o papel desse sujeito como consumidor/receptor e produtor/emissor: a do paradigma clássico da comunicação, baseada no esquema estímulo-resposta e na ideia de manipulação ideológica e controle do destinatário, e a que vê o fenômeno a partir das múltiplas interações comunicacionais e da capacidade do destinatário de ressignificar o conteúdo desses produtos. A reflexão mostra como os fenômenos da mediação e da identificação cultural exercem papeis centrais na complexidade do processo de criação da canção midiática.
\end{abstract}

Palavras-chave: Canção midiática; Teoria da comunicação; Imperialismo cultural; Semiótica; Estudos culturais.

\begin{abstract}
This essay develops a reflection about the role of songwrite in the pop songs under the perspective of main communications and culture theories. It analyzes from the songs creative process to the songs fruition the role of songwriters, considering him embedded in the mass media and cultural industry logic. This reflection contrasts two different points of view about the subject as receiver and transmitter: one that follows the classic communications paradigm, based on stimulus-response scheme and on the ideological manipulation idea, and other which is based on multiple communications interactions paradigm and on the capacity of audience in giving new meanings to the content of mass media and cultural industry products. The essay shows how mediation and cultural identification practice in the pop song creative process.
\end{abstract}

Key-words: Pop song; communications theory; cultural imperialism; semiotics; cultural studies.

\section{RESUMEN}

Este artículo desarrolla una reflexión sobre el papel de compositor de canciones de comunicación desde la perspectiva de algunas de las principales teorías de la comunicación y la cultura. Trata de analizar los elementos que actúan en el proceso creativo del compositor, considerando su inclusión en la lógica

1 Trabalho apresentado à sexta edição da Revista Ação Midiática - Estudos em Comunicação, Sociedade e Cultura, publicação ligada ao Programa de Pós-Graduação em Comunicação, da Universidade Federal do Paraná.

2 Doutorando em Comunicação e Semiótica na Pontifícia Universidade Católica de São Paulo. silvioanaz@hotmail.com 


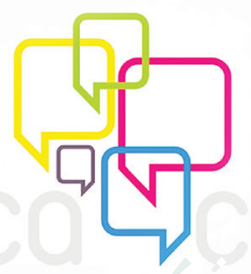

del consumo y de la industria cultural y los medios de comunicación de masas. La reflexión contrasta dos puntos de vista sobre el papel de este sujeto como consumidor / productor y el receptor / transmisor : el paradigma clásico de la comunicación, con base en el esquema estímulo- respuesta y la idea de la manipulación y el control del receptor ideológica, y se ve el fenómeno de la interacción y la comunicación múltiple capacidad del beneficiario de la reformulación de los contenidos de estos productos. La reflexión muestra cómo los fenómenos de la mediación y la identidad cultural juegan un papel central en la complejidad del proceso de creación de la canción de medios.

Palabras clave: Los medios de comunicación de canciones; teoría de la comunicación; el imperialismo cultural; la semiótica; los estudios culturales.

\section{Introdução}

Richard Hamilton, artista e teórico da Pop Arte, no ensaio "For the Finest Art Try Pop", de 1961, afirmou que "o artista da vida urbana do século 20 é inevitavelmente um consumidor de cultura de massa e potencialmente um contribuinte para ela" (MCCARTHY, 2002, p. 26). O compositor das canções populares que têm sido comercialmente bem-sucedidas insere-se exatamente nesse perfil: ele é potencialmente um consumidor das canções e demais produtos da indústria cultural e dos meios de comunicação de massa e inevitavelmente um produtor de canções que se inserem na lógica dessa indústria e desses meios.

O compositor da canção midiática tem sido um dos atores principais na construção dos imaginários que emergem das canções. A construção desses imaginários se dá a partir das diversas relações que o compositor dessas canções estabelece desde a sua formação até o seu processo criativo. Uma dessas relações, por exemplo, é com o repertório de canções populares de sucesso, isto é, com aquelas canções veiculadas à exaustão pelos meios de comunicação de massa.

Este artigo desenvolve uma reflexão sobre o papel do compositor da canção midiáti$\mathrm{ca}^{3}$ como consumidor e produtor de cultura de massa, sob a ótica de algumas das principais teorias da cultura e comunicação. Situar, sob o prisma das teorias da comunicação de massa, essa posição do compositor ajuda a compreender o seu papel no processo de construção dos imaginários na canção midiática.

$\mathrm{Na}$ reflexão a seguir, busca-se colocar frente a frente duas visões sobre esse papel do sujeito como consumidor/receptor e produtor/emissor na lógica da indústria cultural: a que segue o paradigma clássico da comunicação, baseada no esquema estímulo-resposta, na ideia

3 Consideramos como canção midiática, neste artigo, os megagêneros musicais, como o pop e o rock, que dominaram estética e comercialmente o cenário a partir da segunda metade do século 20. São canções que fazem parte do universo mainstream, isto é, são orientadas comercialmente para atingir e fazer sucesso junto a grandes audiências. O pop e o rock, por exemplo, têm abrigado diversos subgêneros e ambos caracterizam-se predominantemente pela exploração da redundância sonora e do pulso rítmico dançante e pelo uso de refrãos e de melodias de fácil memorização. Ao longo dos anos, esses gêneros tornaram-se amplos e diversificados, resultado das várias expressões do comportamento jovem, à medida que este ficou mais complexo. 


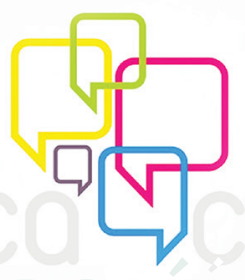

açãơ mididiática

N. 6 | Ano 2013

Universidade Federal do Paraná | Programa de Pós-Graduação em Comunicação

de manipulação ideológica e controle do destinatário, e a que propõe um paradigma baseado em múltiplas interações comunicacionais e na capacidade do destinatário de ressignificar o conteúdo desses produtos.

\section{Os produtos culturais sob o paradigma estímulo-resposta}

Uma das explicações sobre o fenômeno vem da tese do imperialismo cultural - um conceito representativo do paradigma clássico das teorias da cultura e da comunicação de massa.

A ideia do imperialismo cultural surge a partir da década de 1960, quando teóricos da comunicação, como John Tunstall e Herbert Schiller, passam a considerar que produtos da indústria cultural e veiculados pelos meios de comunicação de massa seriam o resultado de uma força cultural imperialista, operando uma ofensiva ideológica por detrás dos produtos dos principais meios de comunicação. Pensadores sobre a cultura e a comunicação, como Pierre Bordieu ${ }^{4}$ e Armand Mattelart ${ }^{5}$, atribuíram ao "imperialismo cultural” uma capacidade de manipulação e de dominação de audiências, principalmente daquelas que estariam nas chamadas nações "periféricas", como as da América Latina.

O imperialismo cultural foi definido como "o uso do poder político e econômico para exaltar e difundir os valores e hábitos de uma cultura estrangeira em detrimento de uma cultura nativa"6 (BULLOCK e TROMBLEY, 1977, p. 303, tradução nossa) e como a "subordinação dos meios de comunicação às influências estrangeiras, particularmente à americana" (INTERCOM, 2010). Para John Tunstall (1977, p. 57), por conta do imperialismo cultural, “culturas autênticas, tradicionais e locais em várias partes do mundo estão sendo destruídas pela venda de largas quantidades de produtos midiáticos e comerciais, principalmente oriundos dos Estados Unidos”. Herbert Schiller, um dos primeiros pesquisadores sobre meios de comunicação de massa a abordar essa questão, em sua análise no final da década de 1960 sobre as relações entre o complexo militar-industrial, dependência cultural e os meios de comunicação, definiu o imperialismo cultural como:

4 Exemplo da visão de Pierre Bordieu é o artigo “A nova Bíblia do Tio Sam” (2000). Nele, Bordieu e Loïc Wacquant afirmam que: "Como as dominações de gênero e etnia, o imperialismo cultural é uma violência simbólica que se apoia numa relação de comunicação coercitiva para extorquir a submissão e cuja particularidade consiste, nesse caso, no fato de universalizar particularismos vinculados a uma experiência histórica singular, ao fazer com que sejam desconhecidos, enquanto tal, e reconhecidos como universais".

5 A ideia de imperialismo cultural tem sido apresentada em várias obras de Mattelart, como no livro "Para Ler o Pato Donald" (1976) e no artigo "O imperialismo cultural na era das multinacionais" (1979).

6 "The use of political and economic power to exalt and spread the values and habits of a foreign culture at the expense of a native culture". 


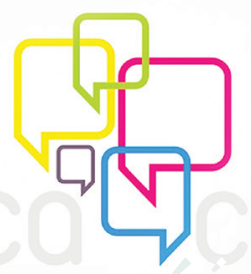

Mediação tecnológica: definida em função das características técnicas (tecnicidade específica) e do ethos do equipamento cultural e comunicacional que está sendo utilizado como meio de veiculação da informação ou de interação entre os interlocutores (da mesma forma que a técnica provoca a natureza, a mediação interpela a cultura).

As mediações ocorrem assim na cotidianidade, nos espaços e tempos em que a cultura se torna concreta, seja no cotidiano familiar, no trabalho, na escola e nas experiências estéticas do indivíduo, entre outros lugares e situações. Ao situar-se como um receptor e ao mesmo tempo um criador dos produtos da indústria cultural, o compositor de canções populares estabelece em seu processo de fruição negociações que são mediadas pelo contexto em que está inserido, pelas estruturas sociais ao seu redor e também por suas atitudes e percepções subjetivas das práticas comunicativas. O compositor atua como um mediador cultural, que Maria Isabel Orofino define como "um agente social que realiza uma ação substantiva e transformadora e não uma ação instrumental e neutra", tanto na esfera da recepção como na da produção (INTERCOM, 2010, p.794).

Outra contribuição seminal para o entendimento da complexidade dos processos comunicacionais e culturais vem da semiótica. A assimetria nos processos de codificação e decodificação dos significados contidos nos produtos culturais, apontada pelos teóricos da escola de Estudos Culturais, também é destacada pelos estudos semióticos. A contribuição do modelo semiótico-textual traz ganhos no entendimento específico dos fenômenos da comunicação de massa (WOLF, 2008, p.124). Esse modelo também aponta para a assimetria que existe entre o emissor e o receptor das mensagens e que reforça a ideia de que os destinatários da mensagem realizam uma interpretação diferente das intenções do emissor, mesmo quando este procura antecipar a compreensão (o processo de decodificação) do receptor ao elaborar a mensagem. Vários fatores concorrem para isso como destacaram Umberto Eco e Paolo Fabbri:

Conforme as diferentes situações socioculturais, existe uma diversidade de códi-
gos, ou melhor, de regras de competência e de interpretação. E a mensagem possui
uma forma significante, que pode ser preenchida com diversos significados, con-
tanto que existam diversos códigos que estabeleçam diversas regras de correlação
entre determinados significantes e determinados significados. E caso existam có-
digos de base aceitos por todos haverá diferenças nos subcódigos (ECO; FABBRI,
s/d, p. 121-122)

Em um processo de comunicação de massa, no qual se insere a canção pop internacional, deve-se considerar ainda alguns outros elementos também destacados por Eco e Fabbri em sua proposta de um modelo semiótico-textual: 


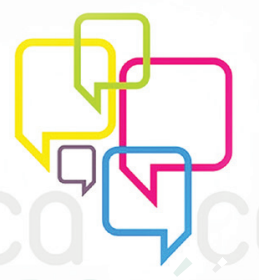

açãơ mididiática

N. 6 | Ano 2013

\section{Universidade Federal do Paraná I Programa de Pós-Graduação em Comunicação}

a. os destinatários não recebem mensagens individuais e reconhecíveis, mas conjuntos textuais;

b. os destinatários não medem as mensagens com base em códigos reconhecíveis como tais, mas em conjuntos de práticas textuais, depositadas (dentro ou na base das quais é indubitavelmente possível reconhecer sistemas gramaticais de regras, mas apenas num nível ulterior da abstração metalinguística);

c. os destinatários nunca recebem uma única mensagem: recebem muitas, tanto no sentido sincrônico como no diacrônico. (ECO; FABBRI, s/d, p. 124)

Sob o prisma dos estudos da recepção, é possível identificar a polissemia dos produtos culturais e as várias interpretações que eles podem ganhar dependendo de uma série de fatores, como a bagagem cultural do receptor ou o contexto social e histórico em que ele está inserido. Canções pop de sucesso nos anos 1980 no Brasil exemplificam esse processo tanto do ponto de vista de quem cria o produto cultural como de quem o consome. Na canção "Rádio Pirata", do grupo RPM, por exemplo, há pelo menos duas avenidas de sentido que podem ser percorridas em um processo de interpretação de sua letra ${ }^{7}$ :

[...] A primeira, mais evidente, percorre o caminho de crítica ao poder estabelecido e às injustiças sociais: seria uma pirataria política contra um rei que significaria o poder estabelecido, o governo. A outra, mais metalinguística, percorreria o caminho da crítica artística, uma crítica ao domínio das programações radiofônicas por determinado tipo de música: seria uma pirataria musical contra as paradas de sucesso: neste caso o 'rei' poderia ser Roberto Carlos, sempre imbatível nas vendagens, mesmo nos anos 80 (ANAZ, 2005, p. 96-97).

Essa multiplicidade de sentidos na letra pode ser gerado tanto no processo de criação como no de interpretação e nem sempre serão coincidentes, uma vez que o criador do produto cultural não tem como controlar a leitura e a interpretação que a audiência faz dele. Desta forma, geralmente uma mesma informação contida em um produto artístico poder ser interpretada de diferentes maneiras, inclusive de uma forma bem distinta da intenção original de seu autor.

A complexidade do processo de interpretação do conteúdo e de percepção da estética de qualquer produto cultural (canção, filme, livro, gibi, telenovela) constatada pelo modelo semiótico-textual fragiliza a ideia de que os produtos culturais sejam um meio eficaz e garantido de disseminar e impor os valores e a visão de mundo de uma determinada cultura central (países do Primeiro Mundo, corporações multinacionais ou transnacionais) ou de elites que dominam a

7 A letra da canção "Rádio Pirata", composta por Paulo Ricardo e Luiz Schiavon e lançada em 1985, traz os seguintes versos: Abordar navios mercantes / Invadir, pilhar, tomar o que é nosso / Pirataria nas ondas do rádio / Havia alguma coisa errada com o rei / Preparar a nossa invasão / E fazer justiça com as próprias mãos / Dinamitar um paiol de bobagens / E navegar o mar da tranquilidade / Toquem o meu coração / Façam a revolução / Que está no ar / Nas ondas do rádio / No submundo repousa o repúdio / E deve despertar /Disputar em cada frequência / O espaço nosso nessa decadência / Canções de guerra / Quem sabe canções do mar / Canções de amor ao que vai vingar / Toquem o meu coração / Façam a revolução / Que está no ar / Nas ondas do rádio / No underground repousa o repúdio / E deve despertar! 

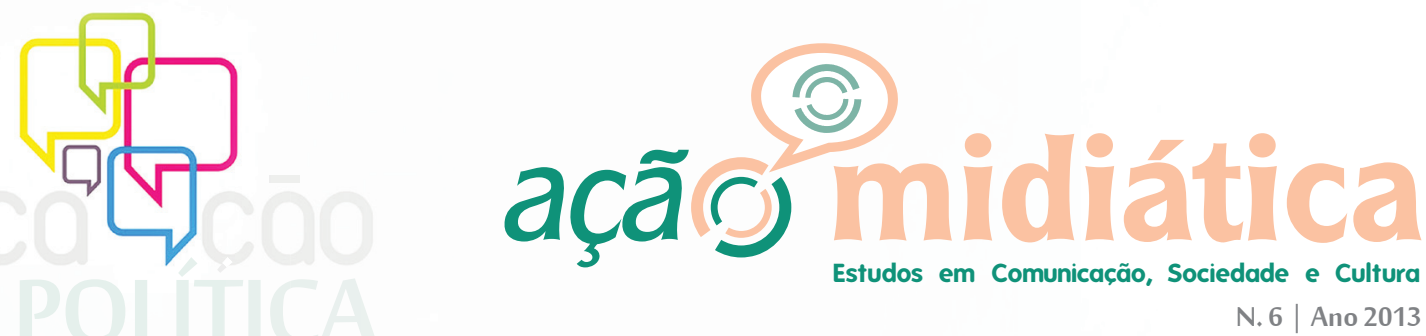

Universidade Federal do Paraná I Programa de Pós-Graduação em Comunicação

indústria cultural e os meios de comunicação de massa a audiências de nações que sejam econômica, política, ideológica e culturalmente subordinadas a ela.

Outro aspecto apontado como negativo na visão do paradigma clássico da comunicação em relação aos fenômenos da indústria cultural diz respeito a um processo de "homogeneização" dos produtos culturais, no qual, no âmbito da canção midiática, o compositor seria um dos principais artífices. Esse, no entanto, é o resultado de uma visão do processo cultural como uma via de mão única, desconsiderando as reações em sentido contrário e as trocas, convergências, sincronizações, apropriações transformações e ressignificações inerentes ao dinamismo das culturas.

\section{Identidade, tribos urbanas e convergência de imaginários na canção}

Os movimentos socioculturais internacionais, que surgem a partir da segunda metade do século 20 influenciados por gêneros da música popular desenvolvidos em segmentos à margem das classes dominantes, como o black power, o punk e o hip-hop, são exemplos de como o fenômeno da homogeneização levou à formação de novos laços sociais e identidades culturais ao mesmo tempo locais e globais, nas quais há uma articulação entre as culturas centrais e periféricas resultando em visões de mundo que não representam necessariamente reprodução nem submissão a uma cultura dos economicamente mais fortes.

Nos parece assim mais adequado entender o papel do compositor e o seu processo de criação da canção midiática de sucesso, ainda que inserido na lógica da indústria cultural, como parte de um fenômeno mais complexo de disseminação e identificação culturais. Um fenômeno que leva o compositor do pop-rock de sucesso da segunda metade do século 20 a identificar-se não mais apenas com os elementos simbólicos locais mas também com os internacionais disseminados pela indústria cultural e pelos meios de comunicação de massa, e que, por conta disso, tornaram-se transnacionais.

Para entendermos melhor isso, é necessário analisar o percurso que na modernidade vai da estreita identificação de culturas com os Estados-nações até a superação disso em um processo de identificação cultural global dos indivíduos, principalmente daqueles que vivem nas metrópoles. Stuart Hall, um dos expoentes da corrente dos Estudos Culturais, em seu estudo da identidade cultural na pós-modernidade, afirma que "no mundo moderno, as culturas nacionais em que nascemos se constituem em uma das principais fontes de identidade cultural" (HALL, 2005, p.47). Essa identificação pode vir da sensação de pertencimento a uma determinada cultura nacional baseada em fatores naturais como o local de nascimento e necessidades e sentimentos primordiais de estabilidade intrínsecos ao ser humano, que, no entanto, não são suficientes para explicar a construção de uma identidade cultural entre um sujeito e uma nação na modernidade. A definição de uma identidade cultural nacional é extremamente complexa e 


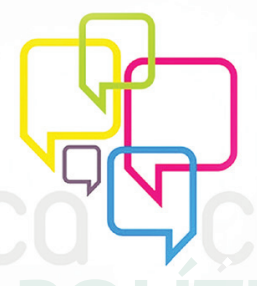

ação mididiática

N. 6 | Ano 2013

\section{Universidade Federal do Paraná I Programa de Pós-Graduação em Comunicação}

polêmica, pois não há nação no planeta em que não exista um pluralismo cultural, fruto de misturas do local com o "estrangeiro". Ao constatar essa condição, de que "as nações modernas são todas híbridos culturais", Hall considera que uma cultura nacional resume-se a "um discurso um modo de construir sentidos que influencia e organiza tanto nossas ações quanto a concepção que temos de nós mesmos" (HALL, p. 50).

As culturas nacionais são, assim, "comunidades imaginadas" unificadas através de um discurso que tem de lidar com o pluralismo cultural que existe dentro de cada uma delas. As tentativas de superar essas divisões internas e diferenças são feitas recorrendo-se a argumentos como etnia e raça, que, no entanto, não se sustentam cientificamente. Junte-se a isso o recorrente apelo nas caracterizações de culturas nacionais a qualidades como "autêntico", "original", "tradições nacionais" ou "folclórico" que buscam limitar espacial e temporalmente a formação da "verdadeira" cultura de uma nação, negando-se o dinamismo inerente ao fenômeno cultural. Tomlinson destaca que "o discurso político de cultura nacional e identidade nacional exige que nós imaginemos esse processo como "congelado""8 (TOMLINSON, 1992, p. 90, tradução nossa) e lembra que as culturas nacionais no mundo moderno nunca são o resultado somente da produção local, pois sempre contêm traços emprestados ou influências de outras culturas (TOMLINSON, 1992, p. 91). Essas contradições enfraquecem a ideia da nação como uma identidade cultural unificada.

Além disso, quanto mais a vida social se torna mediada pelo mercado global de estilos, lugares, imagens, pelas viagens internacionais, pelas imagens da mídia e pelos sistemas de comunicação globalmente interligados, mais as identidades se tornam desvinculadas, desalojadas, de tempos, lugares, histórias e tradições específicos e parecem 'flutuar livremente' (TOMLINSON, 1992, p. 75).

A visão de que há uma imposição da cultura capitalista, fruto da estrutura político-econômica do capitalismo, a outras culturas desde os tempos do colonialismo baseia-se numa ideia romântica de culturas periféricas intocadas, inspirada no que Hall classificou como uma "fantasia colonial" que prevalece no imaginário ocidental "que tende a gostar de seus nativos apenas como 'puros' e de seus lugares exóticos apenas como 'intocados"” (HALL, 2005, p. 80). Essa visão nega a pluralidade que já foi construída historicamente pelas culturas locais e desconsidera que a emancipação proposta pelas condições trazidas pela modernidade possa ser um anseio dos indivíduos dessas culturas. Em “Tudo Que É Sólido Desmancha no Ar”, Marshall Berman (1986) nos lembra que a dominação cultural ocorre muitas vezes quando governos, geralmente autoritários, enveredam por lutas inglórias de preservação de "tradições" frente aos desejos populares pelos valores da modernidade.

8 "The political discourse of national culture and national identity requires that we imagine this process as 'frozen' and this is done via concepts like the 'national heritage' or our 'cultural traditions"”. 


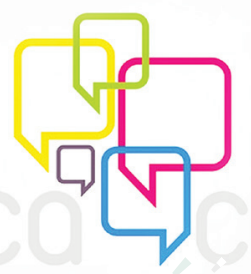

As produções culturais no mundo refletiram, a partir da segunda metade do século 20, de forma intensa a mesma interdependência que está na essência do capitalismo e da modernidade. O sociólogo Immanuel Wallerstein (1991, p. 96) argumenta que a era moderna produziu tanto a formação dos Estados-nações como de um capitalismo que tem aspirações globalizantes, isto é, que superam as fronteiras nacionais. No âmbito da cultura, as novas tecnologias da comunicação, e a interdependência produzida por elas, levou Marshall McLuhan (1962) a ver o mundo como uma "aldeia global". Nesse sentido de "aldeia global", Stuart Hall (2005, p. 57-65) avalia que os fluxos culturais entre os países e a mercantilização dos produtos culturais criam possibilidades de 'identidades partilhadas' entre pessoas que estão bastante distantes umas das outras no espaço e no tempo, o que resulta em um enfraquecimento das identidades culturais "nacionais", já que as culturas dos países estão cada vez mais expostas às influências externas. É nesse processo que aconteceria o fenômeno da homogeneização cultural.

A crítica a essa homogeneização como destruidora da diversidade cultural desconsidera a percepção positiva, e provavelmente consensual, que se tem sobre a adoção universal (uma homogeneização) de várias práticas e atitudes culturais, como os cuidados com a saúde e com a higiene dos alimentos, a valorização da educação e dos processos públicos democráticos e o anseio por valores como honestidade, tolerância e compaixão, entre outros (TOMLINSON, 1992, p. 110). Uma vez que a diversidade por si só não representa necessariamente algo sempre positivo, segundo Tomlinson, o que estaria em jogo na crítica à homogeneização, presente nos discursos sobre o imperialismo cultural, não seria a preservação da diversidade cultural e sim uma condenação do tipo de cultura que se torna homogênea: a cultura capitalista vendida pelas corporações transnacionais ou multinacionais (TOMLINSON, 1992, p. 113).

Mas esse processo de homogeneização ou padronização, que carrega em si a contradição produção-consumo da indústria cultural $^{9}$, resulta no universo do pop-rock quase sempre em uma mescla de culturas heterogêneas e assimétricas e é protagonizado por criadores que vivenciam um processo de identificação cultural desterritorializada.

9 A produção cultural, uma vez inscrita numa estrutura industrial de produção, vê-se organizada a partir de uma concentração técnica e burocrática, que exige padronização, uniformização da produção. Contudo, essa exigência vai sempre se chocar com uma exigência oposta, própria da natureza do consumo cultural, que quer sempre um produto individualizado, personalizado, e sempre novo, original. O funcionamento da indústria cultural teria sempre de operar com essas duas tendências, e o que tornaria possível a organização burocrático-industrial da cultura é a própria estrutura do imaginário do público consumidor, formado por arquétipos, dos quais a indústria cultural se utiliza, estereotipando-os. No consumo: se a lógica do sistema industrial é a do máximo consumo, a indústria da cultura tem de gerar produtos que atendam a um grande número de pessoas, ou ao "homem médio universal", espécie de denominador comum, traço médio universal dos consumidores. É através da homogeneização, do sincretismo, que se consegue quebrar as diversas barreiras culturais numa padronização cosmopolita. A dialética produção-consumo: a cultura de massa não é nem imposta - no sentido de adequar-se totalmente às exigências de produção - nem reflete as necessidades e desejos culturais do público, na medida em que promove uma padronização através do sincretismo. A cultura de massa se adequa a esses desejos, às aspirações, tornando-se local de auto-realização, de concretização daquilo que é suprimido na "vida real". Tem-se, assim, a criação de um novo público, cujo consumo homogeneizado cria uma identidade de valores (de consumo), veiculados pelos meios de comunicação de massa. Há um nivelamento das diferenças sociais, como parte da padronização dos gostos. 


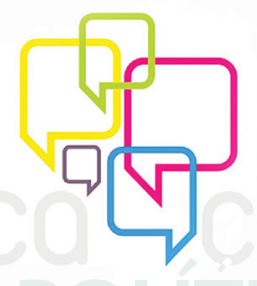

\section{açăo}

Estudos em Comunicação, Sociedade e Cultura N. 6 | Ano 2013

\section{Universidade Federal do Paraná I Programa de Pós-Graduação em Comunicação}

No Brasil, são exemplares desse fenômeno a Bossa Nova, a Jovem Guarda, o Tropicalismo, a Vanguarda Paulistana e o Mangue Beat, movimentos que incorporaram em diferentes graus os elementos da canção internacional de sucesso e, cada um a sua maneira, a eles incorporaram elementos da cultura local. Partindo da constatação de que as culturas se formam e se desenvolvem historicamente a partir de combinações, mesclas, fusões, cruzamentos, intercâmbios e sínteses de diferentes elementos simbólicos, imaginários, repertórios, tradições e experiências culturais, Nestor Canclini desenvolveu o conceito de culturas híbridas ou hibridismo.

Canclini (1997) faz uma crítica às ideias de essência, pureza e autenticidade das culturas. No mesmo caminho aberto pela escola de Estudos Culturais, ele enfatiza a pluralidade da cultura humana. Para Canclini, o fenômeno da hibridação cultural é o resultado de dinâmicas sociais e culturais como as culturas urbanas, as migrações, os processos simbólicos da juventude e o mercado informal. As mesclas culturais que emergem desse processo levam à reconstrução de sentidos das culturas originais.

A música popular norte-americana - com o blues, o jazz, o rhythm'n 'blues, o country e o rock, entre outros gêneros que confluíram na segunda metade do século 20 para o fenômeno da música popular internacional de sucesso - é exemplar disso. O pop e o rock que surgem nos Estados Unidos a partir dos anos 1950, e que se tornam hegemônicos estética e comercialmente em boa parte do planeta, são o resultado de um pluralismo cultural com raízes africanas, europeias e latinas, representativas de diferentes classes sociais, etnias e tradições. Se há alguma mensagem implícita nelas que "penetra no cérebro" de seus ouvintes de forma imperceptível para impor o modo de vida da cultura dos Estados Unidos (american way-of-life), ela está vendendo a ideia de uma cultura pluralista construída a partir dessa miscigenação histórica e social de tradições expressas pela diversidade social e étnica de artistas que a produziram.

O sucesso da canção midiática se dá também como resultado de um fenômeno que o sociólogo francês Michel Maffesoli (2010) chamou de "neotribalização". A ideia de um imaginário que funciona como patrimônio de um grupo, um patrimônio "tribal", constituído por sensações, lembranças, afetos e estilos de vida comuns que se tornam fonte e energia catalisadora de um neotribalismo que supera as tradicionais fronteiras étnicas, nacionais e culturais.

Maffesoli (2010, p. 50) considera que só é possível falar de "imaginário coletivo" e, nesse sentido, equipara o conceito de imaginário ao de "aura" aplicado por Walter Benjamin: algo que não se vê, mas se percebe, uma "atmosfera". Para ele, o "imaginário" assim como a aura ultrapassa o indivíduo, e o que se entende por imaginário individual, na verdade, alimenta e é alimentado pelo imaginário coletivo de um grupo, de uma nação, de uma comunidade, funcionando como um "cimento social" ao estabelecer vínculos. 


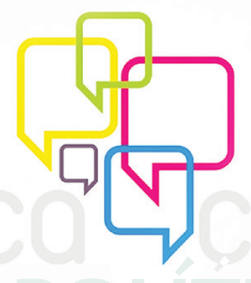

açãô Imidiática

N. 6 | Ano 2013

Universidade Federal do Paraná | Programa de Pós-Graduação em Comunicação

da simples absorção e reprodução de imaginários estrangeiros, a criação ou reprodução de um imaginário pelo compositor de pop-rock no Brasil pode inserir-se em um complexo processo que inclui também um sincretismo ou mescla cultural, fenômeno estudado e denominado por Canclini como hibridismo cultural, no qual há uma síntese de diferentes elementos simbólicos oriundos de culturas estrangeiras e da local.

A partir desse cenário, parece promissor investigar a construção dos imaginários pela canção midiática como resultado de mediações culturais múltiplas entre o compositor e o ecossistema social em que está inserido, o que inclui também um processo de identificação cultural com a estética e a visão de mundo presente na canção internacional. Assim, os imaginários compartilhados nas canções pode ser o resultado de um fenômeno de identificação cultural que é ao mesmo tempo local e global. Pois, como defende Maffesoli (2010), o imaginário é algo que ultrapassa o indivíduo, que impregna o coletivo - ou, ao menos, parte do coletivo. Para o sociólogo francês, pode-se falar em "meu" ou "teu" imaginário, mas, quando se examina a situação de quem fala assim, vê-se que o "seu" imaginário corresponde ao imaginário de um grupo no qual se encontra inserido.

A modernidade, vivenciada a partir da segunda metade do século 20, resultou em um reagrupamento social, em um novo tribalismo, que pode estar sendo fundamental para uma convergência de visões de mundo, para a criação de uma cultura cosmopolita mundial, em um processo de sincronização de imaginários que rompe as fronteiras de nacionalidade, classes sociais, etnia, geracionais e, consequentemente, das culturas. Um cenário no qual os compositores da canção de sucesso participam ativamente na construção de imaginários que são compartilhados globalmente.

\section{Referências bibliográficas}

ADORNO, Theodor W. Prisms. Michigan: MIT Press, 1983.

Indústria Cultural e Sociedade. São Paulo: Paz e Terra, 2002.

ANAZ, Sílvio. Pop Brasileiro dos Anos 80: uma visão semiótica das poéticas das canções mais cultuadas. São Pualo: Editora Mackenzie, 2006.

BERMAN, Marshall. Tudo Que É Sólido Desmancha no Ar. São Paulo: Companhia das Letras, 1986.

BORDIEU, Pierre. O Poder Simbólico. Rio de Janeiro: Bertrand Brasil, 2005.

BORDIEU, Pierre e WAICQUANT, Loïc. "A nova Bíblia do Tio Sam" in Le Monde Diplomatique Brasil, maio de 2000. Disponível em https://www.diplomatique.org.br/acervo. 

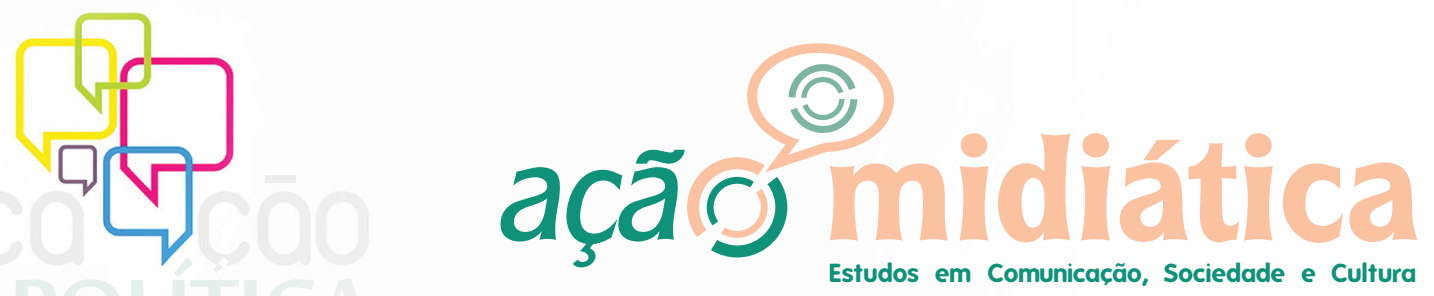

Estudos em Comunicação, Sociedade e Cultura

N. 6 | Ano 2013

Universidade Federal do Paraná I Programa de Pós-Graduação em Comunicação

php?id=271. Acessado em: 13/01/2014.

BULLOCK, Allan e TROMBLEY, Stephen (edit.). The New Fontana Dictionary of Modern Thought. Harper Collins, 1999.

CANCLINI, Néstor. Culturas Híbridas: estratégias para entrar e sair da modernidade. São Paulo: Edusp, 1997.

DORFMAN, Ariel \& MATTELART, Armand. Para Ler o Pato Donald: comunicação de massa e colonialismo. Rio de Janeiro: Paz e Terra, 1976.

HALL, Stuart. A Identidade Cultural na Pós-Modernidade. Rio de Janeiro: DP\&A, 2005.

HALL, Stuart \& Jefferson, Tony (editores). Resistance through Rituals: Youth subcultures in post-war Britain. Nova Your: Routledge, 2000.

HALL, Stuart; HOBSON, Dorothy; LOWE, Andrew \& WILLIS, Paul (editores). Culture, Media, Language. Nova York: Routeledge, 1996.

HARDT, Michael e NEGRI, Antonio. Império. Barcelona: Ediciones Paidós Iberica, 2002.

HARVEY, David. Condição Pós-Moderna. São Paulo: Edições Loyola, 1992.

INTERCOM. Enciclopédia Intercom de Comunicação. São Paulo: Sociedade Brasileira de Estudos Interdisciplinares da Comunicação, 2010.

MAFFESOLI, Michel. O Tempo das Tribos. Rio de Janeiro: Forense Universitária, 2010. 2005.

. A Transfiguração do Político: a tribalização do mundo. Porto Alegre: Editora Sulina,

. "O imaginário é uma realidade (entrevista com Michel Maffesoli)" in Revista $\overline{\text { FAMECOS, n. }}{ }^{\circ}$ 15, agosto de 2001. Entrevista a Juremir Machado da Silva.

MARTIN-BARBERO, Jesús. Dos Meios às Mediações: comunicação, cultura e hegemonia. Rio de Janeiro: Editora UFRJ, 2009.

MATTELART, Armand e Michele. História das Teorias da Comunicação. São Paulo: Edições Loyola, 1999.

MATTELART, Armand. "O imperialismo cultural na era das multinacionais" in

WERTHEIN, J. (org). Meios de comunicação: realidade e mito. São Paulo: Nacional, 1979.

MCCARTHY, David. Arte Pop. São Paulo: Cosac \& Naif, 2002. 

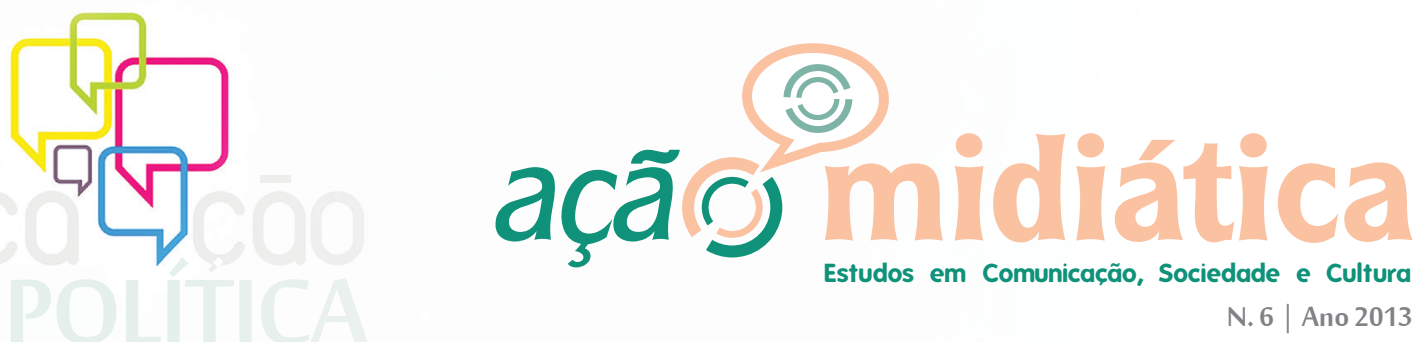

Universidade Federal do Paraná I Programa de Pós-Graduação em Comunicação

MCLUHAN, Marshall. A Galáxia de Gutenberg: a formação do homem tipográfico. São Paulo: Editora Nacional, 1977.

OROZCO GÓMEZ, Guillermo. Recepción televisiva y mediaciones: la construción de estrategias por la audiencia in Televidencia - Cuadernos de Comunicación, n. 6, México, 1994.

SCHILLER, Herbert. "Communication and Cultural Domination" in International Journal of Politics, Vol. 5, No. 4, (Winter 1975/1976), pp. 1-127.

TOMLINSON, John. Cultural Imperialism: A Critical Introduction. Nova York: American Council of Learned Societies, 1992.

WALLERSTEIN, Immanuel. The National and the Universal in (KING, Anthony D.). Culture, Globalization and the World System. Londres: Macmillam, 1991.

WOLF, Mauro. Teorias das Comunicações de Massa. São Paulo: Martins Fontes, 2008. 